\title{
Urinary amino acid excretion in subjects with leukaemia
}

\author{
MAUREEN B. LEE, D. W. NEILL, AND J. M. BRIDGES \\ From the Department of Clinical Pathology, Royal Victoria Hospital, Belfast
}

SYNOPSIS Urinary amino acid chromatograms were studied from 33 patients with various types of leukaemia and 71 control subjects. Marked variations were found in the excretion of methionine, i threonine, valine, leucine, tyrosine, histidine, and aspartic acid.

The aim of drug therapy in patients with leukaemia is to destroy the leukaemic cell by interference with its metabolic functions, and recently, there have been reports of attempts to inhibit their growth and reproduction by alteration in the amino-acid content of the diet (Allan, Ireland, Milner, and Moss, 1965; Halikowski, Aramata, and Garwicz, 1966; Hilson, 1966). Although it is too early to evaluate this work, the results have been sufficiently encouraging to warrant further trial.

Basic knowledge of the amino-acid metabolism and deviation from normal, if any, in leukaemic subjects is scanty. It was felt that further investigations would assist in planning rational therapy along these lines and at the same time provide further fundamental information about the disease process.

In this paper we report the results of a preliminary study in which the excretion of amino-acids in the urine of patients suffering from leukaemia is compared with that of normal subjects.

\section{MATERIALS AND METHODS}

MATERIALS Urine samples were obtained at various times during the day from all subjects without regard to previous protein intake. Thirty-three subjects with leukaemia proven by full haematological and bone marrow investi-

\section{TABLE I}

ANALYSIS OF SAMPLE STUDIED

\begin{tabular}{lcrlrl} 
Disease & $\begin{array}{l}\text { No. of } \\
\text { Patients }\end{array}$ & \multicolumn{2}{l}{\begin{tabular}{l} 
Sex \\
\cline { 3 - 4 }
\end{tabular}} & & $\begin{array}{l}\text { Age Range } \\
\text { (years) }\end{array}$ \\
\hline Acute blastic leukaemia & 16 & 10 & 6 & 1 to 74 \\
Chronic granulocytic leukaemia & 10 & 4 & 6 & 40 to 76 \\
Chronic lymphatic leukaemia & 7 & 6 & 1 & 42 to 73
\end{tabular}

gations were studied; details of the subjects are shown in Table I. A total of 160 chromatograms was prepared. The Received for publication 20 July 1966. patients were receiving supportive therapy such as blood transfusion and specific anti-leukaem:c drugs. Specimens were obtained at different stages of the disease: at the onset, during remission and relapse, and in the terminal stages of the illness.

Seventy-one normal control subjects were also studied. These were mainly healthy hospital staff, with a few elderly subjects who had had recent minor fractures, with equal numbers of men and women ranging in age from 17 to 75 years. One specimen was examined from each subject.

METHOD The total non-protein nitrogen was estimated by the method of digestion and nesslerization (Carson, 1963). The volume of urine containing $250 \mu \mathrm{g}$. of nonprotein nitrogen was applied to each 8 in. square of Whatman no. 541 chromatography paper.

For qualitative chromatography of all urines, the method was essentially that used by Dent (1948) and Datta, Dent, and Harris (1950), modified to make it semiquantitative (Cusworth, 1957). All samples were desalted by electrodialysis, using ion exchange membranes (Blainey and Yardley, 1956) and Smith's (1960) modification of Wood's method (1960) before spotting.

Five $\mu$ l. of hydrogen peroxide was applied to each square to convert methionine to methion ne sulphone and cystine to cysteic acid. Methionine (as the sulphone) then travels close to the valine position rather than beside leucine and iso-leucine. The leuc.nes and methionine sulphoxides are unchanged.

The first solvent used was phenol (G.P.R. grade), dissolved in $25 \%$ its weight of water. Just before the tank was closed, 2 drops of concentrated ammonia, $\mathrm{NH}_{4} \mathrm{OH}$ (specific gravity 0.880 ) were added down the side. This has the effect of slowing down the movement of aspartic and glutamic acids and hastening that of the basic amino acids. The second solvent was saturated 2:4/2:5 lutidine (supplied by Yorkshire Tar Distillers). After each run, the papers were dried by placing them in front of an electric fan overnight.

The amino acids on the developed chromatogram were converted to the coloured ninhydrin complexes by dipping 
in $0.2 \%$ solution of ninhydrin in acetone. After drying at room temperature for 20 minutes, they were heated at $70^{\circ} \mathrm{C}$. for 10 minutes.

The spots were identified by comparison with a preconstructed map of known amino acids. To assist in comparing spot densities, $5 \mu \mathrm{l}$. of $\alpha$-amino octanoic acid was applied to each paper. The density of this developed spot was taken as 5 , and the density of the other spots numbared from 1 to 10 by reference to it. This assessment was carried out by the same person for all papers, and allowed the excretion of each amino acid to be recorded as a number.

The results for each group of patients thus took the form of number values, assigned to each of 16 amino acids. It was decided that the most valid measure of the excretion of any amino acid would be obtained by dividing the total of the numbers assigned to each amino acid in each subject group by the number of chromatograms obtained from the subjects in that group. This 'average score' is used in the subsequent discussion.

\section{RESULTS}

Table II shows the average value for total nonprotein nitrogen in the subjects in the various groups.

\section{TABLE II}

AVERAGE VALUE FOR TOTAL NON-PROTEIN NITROGEN

\begin{tabular}{llc}
$\begin{array}{l}\text { No. of } \\
\text { Subjects }\end{array}$ & Disease & $\begin{array}{c}\text { Total Nitrogen } \\
(\mathrm{g} / \mathrm{ll} .)\end{array}$ \\
\hline 71 & Controls & $11 \cdot 2$ \\
16 & Acute blastic leukaemia & $10 \cdot 2$ \\
10 & Chronic granulocytic leukaemia & $8 \cdot 4$ \\
7 & Chronic lymphatic leukaemia & $10 \cdot 4$
\end{tabular}

The leukaemic groups had a slightly lower total nitrogen content, but this was not considered to be significant.

The average score for each amino acid in the various groups is given in Table III. The control subjects were divided into four sections at random to detect any gross variation in amino acid excretion. Variations were found only in the excretion of arginine/ lysine, glutamic acid, and taurine. For these com- pounds the values for the leukaemic group were compared with the upper or lower extreme of normal groups (Figs. 1, 2, 3).

The principal amino acids excreted by our control group were glycine, glutamine, taurine, alanine, serine, aspartic acid, histidine, with smaller amounts of glutamic acid, valine, the leucines, and tyrosine. In occasional samples, there were traces of arginine/ lysine, methyl histidine, methionine, and threonine.

In the subjects with leukaemia, values for arginine/ lysine, methyl histidine, glycine, taurine, and alanine were not significantly altered compared with those of the control subjects.

Histidine, aspartic acid, leucine, tyrosine, and valine were lower in all leukaemic groups. The glutamine level was low for the leukaemic groups except perhaps in chronic lymphatic leukaemia whereas serine was low only in this group.

The levels of threonine and methionine were raised significantly in all leukaemic groups. The level of glutamic acid was raised in those with acute and chronic granulocytic leukaemia but only slightly so in those with chronic lymphatic leukaemias.

These differences in the excretion of leucine, tyrosine, valine, threonine, and methionine are also reflected in the relative numbers of subjects in each group in whose urine they were found (Table IV).

\section{DISCUSSION}

In subjects with leukaemia the total non-protein urinary nitrogen concentration was slightly lower than in the control group (Table II). However, assuming a normal total urinary output, these values would all fall within the normal range of 9 to $18 \mathrm{~g}$./24 hours (Bigwood, Crokeart, Schram, Soupart, and Vis, 1959). Nour-Eldin and Wilkinson (1955) found the urinary amino nitrogen level to be normal in seven leukaemic subjects.

The chromatographic assessment used in the present study is obviously highly subjective. Thus, in

\section{TABLE் III}

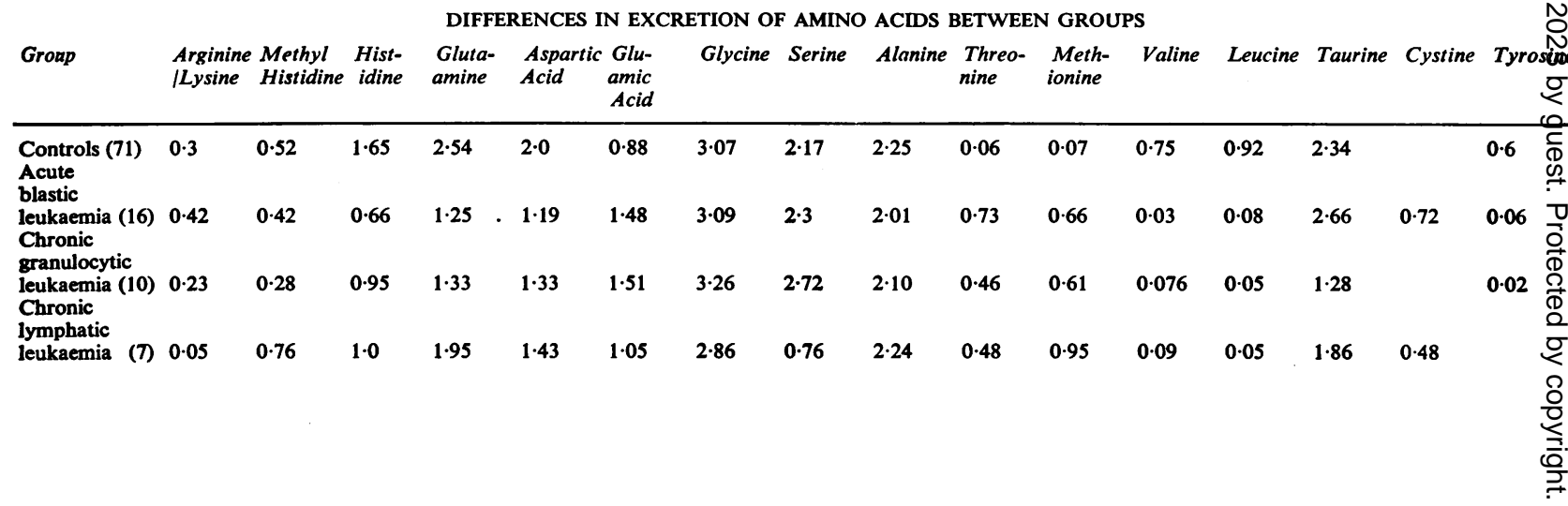




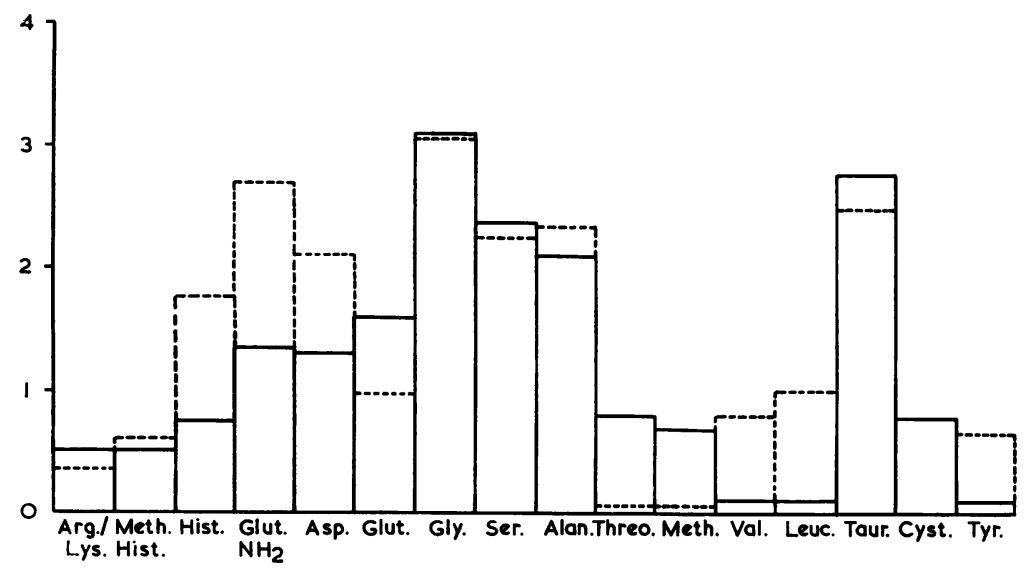

FIG. 1. The distribution of the excretion of the amino acids in subjects with acute blastic leukaemia compared with the distribution in control subjects (average score shown on left-hand side).

-acute blastic leukaemia.

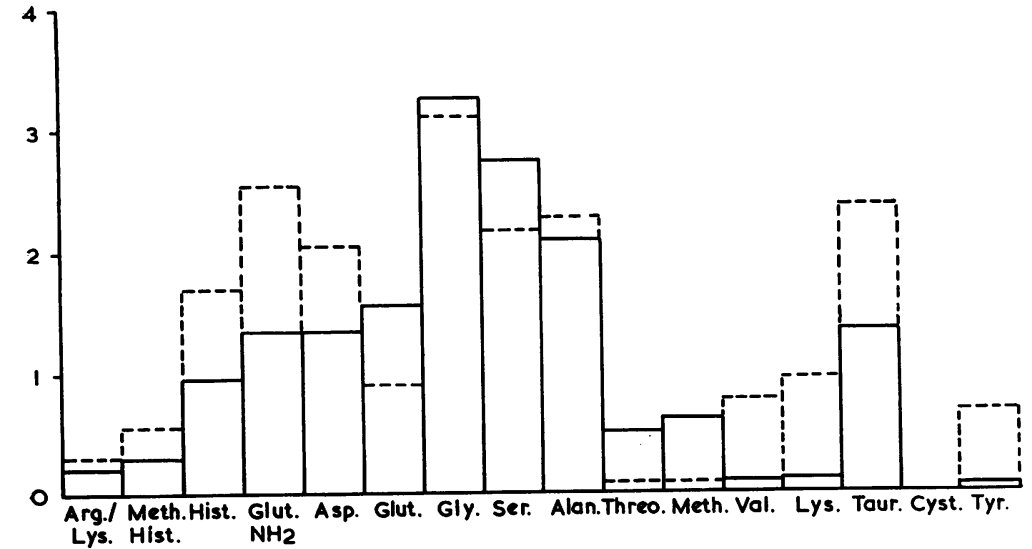

FIG. 2. The distribution of the excretion of the amino acids in subjects with chronic granulocytic leukaemia compared with the distribution in control subjects (average score shown on lefthand side).

chronic granulocytic leukaemia.

--- normal

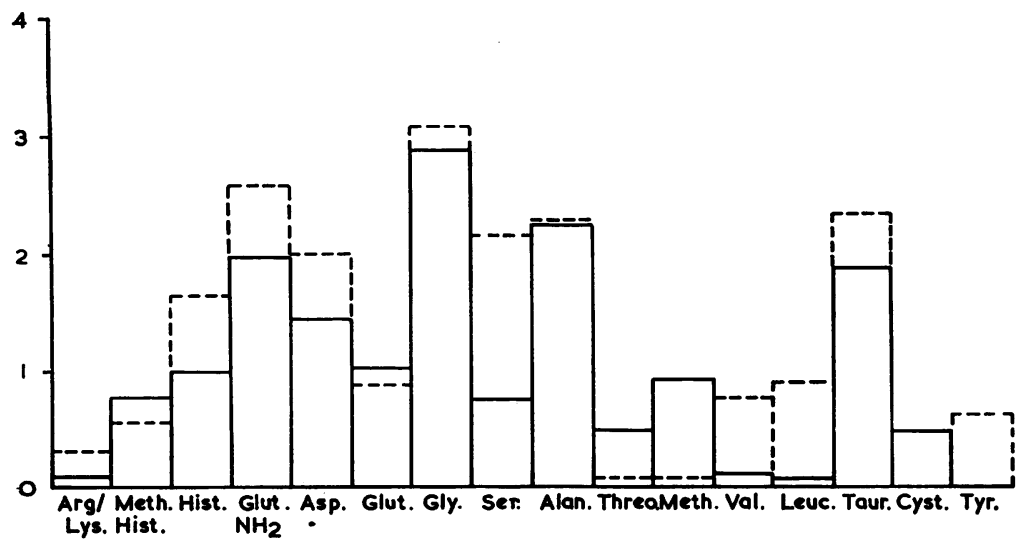

FIG. 3. The distribution of the excretion of the amino acids in subjects with chronic lymphatic leukaemia compared with the distribution in control subjects (average score shown on left-hand side).

chronic lymphatic leukaemia.

- - - normal. 


\section{TABLE IV}

NUMBERS OF SUBJECTS IN EACH GROUP RELATED TO EXCRETION OF CERTAIN AMINO ACIDS

\begin{tabular}{ll} 
Amino Acid & Present in: \\
\hline Threonine & 2 of 71 controls \\
10 of 16 cases of acute blastic leukaemia \\
5 of 10 cases of chronic granulocytic leukaemia \\
4 of 7 cases of chronic lymphatic leukaemia \\
Methionine & 3 of 71 controls \\
& 9 of 16 cases of acute blastic leukaemia \\
& 4 of 10 cases of chronic granulocytic leukaemia \\
& 4 of 7 cases of chronic lymphatic leukaemia \\
Valine & 51 of 71 controls \\
& 2 of 16 cases of acute blastic leukaemia \\
& 3 of 10 cases of chronic granulocytic leukaemia \\
& 1 of 7 cases of chronic lymphatic leukaemia \\
Leucine & 61 of 71 controls \\
& 6 of 16 cases of acute blastic leukaemia \\
& 1 of 10 cases of chronic granulocytic leukaemia \\
& 1 of 7 cases of chronic lymphatic leukaemia \\
& 54 of 71 controls \\
& 4 of 16 cases of acute blastic leukaemia \\
Tyrosine & 1 of 10 cases of chronic granulocytic leukaemia \\
& 0 of 7 cases of chronic lymphatic leukaemia
\end{tabular}

view of the small number of patients in some groups, only a very large deviation from the normal value can be counted as significant, and we have arbitrarily used a deviation of greater than $30 \%$ as abnormal. Carson (1963), Baron, Dent, Harris, Hart, and Jepson (1956), and Allan, Cusworth, Dent, and Wilson (1958) have used this type of approach to study aminoaciduria in a variety of conditions. In assessing the significance of the results it is important to have regard to the heterogeneity of the patients within the groups, and thus our abnormal findings cannot automatically be ascribed to the effects of the leukaemic process. Abnormalities in urinary aminoacid excretion can reflect either metabolic changes or secondary effects on renal tubular absorption.

The amino-acid distribution in the 71 control subjects was very similar to that found by Dent (1948), Carson (1963), Smith (1960), and Bigwood et al. (1959).

In the leukaemic subjects the levels of glycine, alanine, taurine, methyl histidine, and arginine/ lysine were not significantly different from those found in the control subjects. Rouser (1957) found increased urinary levels of alanine in some cases of leukaemia but this has not been confirmed in the present study.

The finding of a normal level of taurine is of interest, as its level of excretion can clearly be related to dietary habits. One might expect that a group of people with leukaemia, some of whom were extremely ill, would have a lower than normal intake of protein, and thus excrete less taurine. An increased excretion of taurine is, however, a well-known phenomenon in patients with liver disease (Dent, 1948) and megaloblastic anaemia (Neill and Weaver, 1959). Thus one might expect a group of leukaemic subjects, many of whom showed clinical and biochemical evidence of hepatic dysfunction and upset of folic acid metabolism, to have a high level of excretion of taurine.

The leukaemic subjects showed a decreased excretion of histidine, aspartic acid, leucine, tyrosine, and valine from that which was found in the control subjects.

It is known that in clinical situations in which there is an increased utilization of folic acid, there is an increased excretion of histidine (Chanarin and Rothman, 1964). The degradation of histidine via urocanic acid and formiminoglutamic acid (Figlu) to glutamic acid requires folic acid for the last step. Rose (1966) has reported that a folic acid deficiency is commonly associated with leukaemia, the cause of which is not yet established. Leukaemic cells have a higher folic acid content than normal leucocytes (Swendseid, Bethell, and Bird, 1951). In view of our finding that the output of histidine is consistently reduced, it would seem that this aspect of metabolism in leukaemia would repay further investigation.

A low level of aspartic acid has been noted in all types of leukaemia studied. Aspartic acid provides nitrogen for purine synthesis, and is a precursor of orotic acid and pyrimidine, D.N.A. and R.N.A. containing both these ring systems. It is tempting to speculate that the formation of large numbers of leucocytes in leukaemia will require increased quantities of these nucleotides with a consequent reduction in the excretion of aspartic acid.

Waisman (1957) commented on the absence of raised tyrosine levels in the urine of leukaemic patients who had a raised plasma level of this compound. In the present study, plasma levels were not determined, but it was confirmed that there was no increase in tyrosine excretion.

The finding of low levels of glutamine agrees with Rouser's statement (1957) that glutamine is virtually absent from lymphocytes, red cells, urine, and plasma in leukaemic subjects. It is difficult to comment on the significance of reduced glutamine excretion since the relative quantities of glutamine and glutamic acid depends on the age of the sample, fresh samples of urine containing little or no glutamic acid. It is unlikely however, that any marked difference in age of the sample characterized any one of our groups. Glutamic acid is the end product of histidine metabolism and the finding of high levels of glutamic acid may be related to the finding of a low histidine excretion or may be the result of a change in the transamination from glutamine.

The level of methionine was found to be consist- 
ently raised in all the leukaemic groups studied. It is an essential amino acid as it occupies a unique position in methylation processes. It is striking that raised methionine levels have been found most consistently in patients with chronic granulocytic leukaemia in whom very high levels of serum $B_{12}$ have been reported (Beard, Pitney, and Sanneman, 1954; Mollin and Ross, 1955). Cysteine and methionine are readily interconverted; but the dietary need for methionine can only be met by cysteine if the number of labile methyl groups is sufficient, or large amounts of vitamin $B_{12}$ and folic acid are present. In this connexion, it has been shown that the leucocytes of patients with chronic granulocytic leukaemia show a significantly raised content of S-adenosylmethionine (Baldessarini and Carbone, 1965). Methyl mercaptan is one product of methionine degradation and the administration of mercaptans therapeutically may block the metabolism of methionine and result in an accumulation of this amino acid.

The serine excretion was found to be normal in all the leukaemia groups except chronic lymphatic leukaemia where it was very much reduced.

Awapara (1957) reported that all the leukaemic patients studied excreted varying amounts of $\beta$-aminoisobutyric acid, which was not detectable in normal subjects. Awapara and Sato (1956) had previously reported that a study of one leukaemic patient over 10 days had shown that large amounts of $\beta$-aminoisobutyric acid were excreted for the first five days only, excretion of all the other acids remaining constant. Killmann, Rubini, Cronkite, and Bond (1961) found that in two out of three untreated patients with chronic granulocytic leukaemia, that there was a very marked increase in the urinary excretion of $\beta$-aminoisobutyric acid but after therapy with Busulphan this returned to normal. We found no excretion of this acid in any of the leukaemic subjects.

Cysteic acid was excreted by a few subjects in each leukaemic group but was in each case related to the injection of penicillin and may well have been the derivative of cysteic acid (tetra methyl).

In considering our results it is important to have regard to the limitations of the present study. The number of patients in each group was small and each group was composed of patients in whom the disease process was of differing degrees of severity. The patients were having, or had had, various chemotherapeutic regimes and blood transfusion, and the incidence of anaemia and infection differed also. Thus no group could be considered homogeneous. It is nevertheless true that some of the abnormalities referred to appeared with such consistency that it is difficult to see how they can be dissociated from some fundamental process.

A further study, using more elaborate techniques to follow the metabolic pathway of the individual amino acids, is being undertaken in an attempt to evaluate the significance of the findings reported here.

We are indebted to Dr. M. G. Nelson for his continuing interest and advice.

M.B.L. is a Research Fellow of the Northern Ireland Leukaemia Research Fund whose generous financial support made it possible to carry out this work.

Miss D. Bolger gave skilled technical assistance.

\section{REFERENCES}

Allan, J. D., Cusworth, D. C., Dent, C. E., and Wilson, V. K. (1958). Lancet, 1, 182.

- Ireland, J. T., Milner, J., and Moss, A. D. (1965). Ibid., 1, 302.

Awapara, J. (1957). In The Leukemias. Henry Ford Hospital International Symposium, edited by J. W. Rebuck, F. H. Bethell, R. W. Monto, p. 353. Academic Press, New York.

Awapara, J., and Sato, Y. (1956). Clin. chim. Acta, 1, 75.

Baldessarini, R. J., and Carbone, P. P. (1965). Science, 149, 644.

Baron, D. N., Dent, C. E., Harris, H., Hart, E. W., and Jepson, J. B. (1956). Lancet, 2, 421.

Beard, M. F., Pitney, W. R., and Sanneman, E. H. (1954). Blood, 9, 789.

Bigwood, E. J., Crokeart, R., Schram, E., Soupart, P., and Vis, H. (1959). Advanc. clin. Chem., 2, 201.

Blainey, J. D., and Yardley, H. J. (1956). Nature (Lond.), 177, 83.

Carson, N. A. J. (1963). A Biochemical Study of Mentally Retarded Individuals in Northern Ireland. M.D. Thesis, Queen's University, Belfast.

Chanarin, I., and Rothman, D. (1964). J. clin. Path., 17, 196.

Cusworth, D. C. (1957). Amino acid excretion in man. Ph.D. Thesis, London University.

Datta, S. P., Dent, C. E., and Harris, H. (1950). Science, 112, 621.

Dent, C. E. (1948). Biochem. J., 43, 169.

Halikowski, B., Armata, J., and Garwicz, S. (1966). Brit. med. J., $1,519$.

Hilson, D. (1966). Ibid., J., 1, 979.

Killmann, S. A., Rubini, J. R., Cronkite, E. P., and Bond, V. P. (1961). Acta haemat. (Basel), 25, 81.

Mollin, D. L., and Ross, G. I. M. (1955). Brit. J. Haemat., 1, 155.

Neill, D. W., and Weaver, (1959). Acta. Haemat., 21, 33.

Nour-Eldin, F., and Wilkinson, J. F. (1955). Ibid., 1, 367.

Rose, D. P. (1966). J. clin. Path., 19, 29.

Rouser, G. (1957). In The Leukemias. Henry Ford Hospital International Symposium, edited by J. W. Rebuck, F. H. Bethell, and R. W. Monto, p. 361. Academic Press, New York.

Smith, I. (1960). Chromatographic and Electrophoretic Techniques, 2nd ed. Heinemann, London.

Swendseid, M. E., Bethell, F. H., and Bird, O. D. (1951). Cancer Res., $11,864$.

Waisman, H. A. (1957). In The Leukemias. Henry Ford Hospital International Symposium, edited by J. W. Rebuck, F. H. Bethell, and R. W. Monto, p. 339. Academic Press, New York. Wood, T. (1960). Nature (Lond.), 186, 634. 